\title{
Association between work time loss and quality of life in patients with Herpes Zoster: a pooled analysis of the MASTER studies
}

Emmanouil Rampakakis ${ }^{1}$, Melissa Stutz ${ }^{1}$, Kosuke Kawai $^{2}$, Tsen-Fang Tsai ${ }^{3}$, Hee Jin Cheong ${ }^{4}$, Jittima Dhitavat ${ }^{5}$, Alejandro Ortiz-Covarrubias ${ }^{6}$, Miguel Cashat-Cruz ${ }^{7}$, Homero Monsanto ${ }^{8}$, Kelly D. Johnson? ${ }^{9}$, John S. Sampalis ${ }^{10,1^{*}}$ and Camilo J. Acosta ${ }^{9}$

\begin{abstract}
Background: Herpes zoster ( $\mathrm{HZ}$ ) has a significant negative effect on the productive work life of individuals, and has been shown to be responsible for cases of absenteeism, presenteeism and decreased work effectiveness. The aim of this study was to evaluate health utility scores and associated predictors in an actively employed population of Herpes Zoster (HZ) patients with and without work time loss (WTL).

Methods: This was a pooled analysis of the prospective, observational MASTER cohort studies, conducted in 8 countries across North America, Latin America and Asia. A total of $428 \mathrm{HZ}$ patients engaged in full or part time work were included. WTL, defined as missing $\geq 1$ partial or full work day, and work effectiveness, reported on a scale of 0-100\%, were evaluated with the Work and Productivity Questionnaire (WPQ). The Pearson product-moment correlation was used to assess the correlation between work effectiveness and HRQOL. Mixed models with repeated measures assessed the relationship between HZ-related WTL over a 6-month follow-up period, and HRQoL, as evaluated by the EQ-5D. Additional predictors of HRQoL were also identified.
\end{abstract}

Results: Overall, $57.7 \%$ of respondents reported WTL. Mean (SD) percent work effectiveness of patients in the WTL group was significantly lower compared to non-WTL (NWTL) patients at baseline [50.3 (31.6) vs. 71.4 (27.8); $p<0.001]$. Patients in the WTL group also reported lower health utility scores at baseline and overall than their NWTL counterparts, with WTL identified as an independent negative predictor of both the EQ-5D summary scores and the EQ-5D VAS $(p<0.001)$. Decrease in work effectiveness was negatively associated with HRQoL overall $(p<0.001)$. Predictors of lower HRQoL were worst Zoster Brief Pain Inventory (ZBPI) pain score, the presence of HZ complications and country income (predictor of EQ-5D VAS only).

Conclusions: $\mathrm{HZ}$ adversely impacts the work and productive life of actively employed individuals. In turn, $\mathrm{HZ}$-related reductions in work effectiveness and work time are associated with a negative effect on HRQoL.

Keywords: Herpes Zoster, Quality of life, Work, Observational study

\footnotetext{
* Correspondence: submission@jssresearch.com

${ }^{10}$ McGill University, 845 Sherbrooke Street W, Montreal, QC H3A 0G4, Canada

'JSS Medical Research, 9400 Henri-Bourassa W, St-Laurent, QC H4S 1N8,

Canada

Full list of author information is available at the end of the article
} 


\section{Background}

$\mathrm{HZ}$ or shingles is caused by the reactivation of the varicella zoster virus (VZV), for which primary infection manifests as chickenpox, or varicella. The estimated lifetime risk for the development of $\mathrm{HZ}$ is approximately $30 \%$ [1-3]. Rash onset, the typical clinical feature of $\mathrm{HZ}$, is characterized by a unilateral, dermatomal rash with vesicular lesions that usually heal within 2-4 weeks [4]. Pain during this phase, which ranges from moderate-to-severe in the majority of patients [5], negatively impacts functional status and QoL with greater acute pain burden significantly associated with poorer physical role, social functioning, and greater emotional distress [5-8]. HZ has also been shown to be responsible for cases of absenteeism, presenteeism (defined as attending work while sick) and decreased work effectiveness [9-11], with combined work loss varying significantly by disease severity [10]. Consequently, HZ has a significant negative effect on the productive work life of individuals; consideration of this effect on work and productivity therefore contributes to the cost-effectiveness of $\mathrm{HZ}$ therapeutic interventions, specifically those aiming at preventing VZV reactivation.

However, the true cost-effectiveness of therapeutic interventions for $\mathrm{HZ}$ may be underestimated. This is emphasized by discrepancies in guidelines for costeffectiveness analysis, which differ as to whether work time loss should be included in the numerator of the incremental cost-effectiveness ratio (ICER), or as an implicit consideration of health state valuations, which are contained in the denominator of the ICER. This is due to the fact that it is unclear whether or not people actually take into account the effect of disease on their ability to work, and the resulting lost wages, when evaluating health states [12-14]. The Panel on Cost-Effectiveness in Health and Medicine have nevertheless recently put forth revised recommendations advocating for the inclusion of these effects in the numerator in the ICER [15].

The MASTER (Monitoring and Assessing Shingles Through Education and Research) studies, were prospective cohort studies conducted in 8 countries [16-19], which assessed Herpes Zoster (HZ)-related burden of illness, including pain, health related quality of life (HRQoL), health care resource utilisation (HCRU), and associated cost. Using data from these studies, the aim of this pooled analysis was to examine the association of HZ-related work time loss, or HZ-related work productivity loss, with HRQoL, to evaluate whether or not patients with work time loss have lower health utility scores than those without, and to identify predictors of HRQoL in an active population of $\mathrm{HZ}$ patients.

\section{Methods}

Study design

This is a pooled analysis of the MASTER studies conducted in 8 countries, which shared the same design and were conducted using similar methodology [16-19]. The objectives of the MASTER study were to measure HZrelated burden of illness, HRQoL, health care resource utilisation (HCRU), and out of pocket costs. Among the 1477 patients enrolled overall, 428 were engaged in full or part time work (active population) and were, thus, included in the current analysis, with the following geographic distribution: Latin America $(n=128)$, consisting of Argentina $(n=37)$, Brazil $(n=36)$, Costa Rica $(n=6)$, and Mexico $(n=49)$; North America, consisting of Canada $(n=160)$; and Asia $(n=140)$, consisting of Korea $(n=45)$, Taiwan $(n=49)$, and Thailand $(n=46)$.

\section{Patient population}

Patients eligible for cohort inclusion were either male or female patients $\geq 50$ years of age with $\mathrm{HZ}$ rash or residual HZ-associated pain, defined as pain persisting subsequent to rash healing. In addition, in order to be included in this analysis, patients had to belong to the active population (actively employed in full or part time work). Incident cases were defined as patients recruited from the offices of general practitioners or specialists for a current $\mathrm{HZ}$ episode (rash onset or start of pain) with a duration of $\leq 7$ days; prevalent cases were defined as patients enrolled experiencing a HZ episode which had lasted longer than 7 days, with the onset of rash recorded in medical records. Key exclusion criteria were the presence of any medical condition that, in the opinion of the treating physician, could interfere with the evaluations required by the study, and patient and/or family member or primary caregiver refusal to sign informed consent.

\section{Treatment and follow-up}

In accordance with the observational nature of the studies, any treatment of the HZ-episode was based on the judgement of the treating physician. After the baseline assessment at Day 0, patients were followed for a maximum of 6 months. Regardless of the phase of disease at the time of enrolment, 9 follow-up assessments were recommended at Days 7, 14, 21, 30, 60, 90, 120, 150 and 180 , to a total of 10 visits, with the exception of Korea and Taiwan, in which prevalent cases were assessed at every month after the baseline visit, for a total of 7 visits overall. The baseline (Day 0) assessment was conducted at the physician's office, and follow-up assessments were conducted though self-administered questionnaires. At baseline, information regarding the patient's immune status, pain-related medical history, demographics, current medications, and characteristics of the current 
HZ-episode, was collected. The outcome measures described in the following section were evaluated at each patient assessment.

\section{Pooled analysis outcome measures Work productivity and work time loss}

Work productivity of patients and/or caregivers was measured at every patient assessment irrespective of the presence of $\mathrm{HZ}$ rash and/or pain using a simple descriptive, self-administered, standardized questionnaire, the Work and Productivity Questionnaire (WPQ) (Additional file 1). The WPQ evaluated the number of times work was missed (full and half days), with Work Time Loss defined as missing $\geq 1$ partial or full work day. The principal causes of absences (health care visits, pain, discomfort, lack of concentration, visible rash, or medication side effects), and whether or not extended sick leave, disability, or use of vacation time was required, was also assessed. In addition, patients were asked to rate their productivity (effectiveness) at work during their shingles episode on a scale of $0-100 \%$.

\section{Health related quality of life}

HRQoL was captured using the Euro-QoL (EQ-5D) questionnaire [20], a generic health status instrument which evaluates quality of life based on the measurement of five dimensions: mobility, self-care, usual activities, pain/discomfort and anxiety/depression. A preference based scale, the EQ-5D assesses each dimension with three levels of severity; 1 (no problems), 2 (some problems), and 3 (maximum problems). Each score can then be weighted to adjust for populationspecific preferences in health-care states. For the purposes of this analysis, UK weights, the most validated weights, were used to convert individual health dimensions scores to a single EQ-5D summary score, with EQ5D summary scores closest to 1 indicative of a better quality of life. The VAS component of the EQ-5D questionnaire (EQ-5D VAS) also records the patient's selfrated health on a horizontal scale, ranging from "worst imaginable health state" to "best imaginable health state". At the baseline visit (Day 0), each patient was required to complete two EQ-5D questionnaires, one to assess their usual quality of life prior to $\mathrm{HZ}$ onset, and another to assess their current state of health during the current HZ episode.

\section{HZ-associated pain}

HZ-associated pain was evaluated with the Zoster Brief Pain Inventory (ZBPI) questionnaire [21] and the Initial Zoster Impact Questionnaire (IZIQ). The ZBPI is a 9 question HZ-specific questionnaire which evaluates two components of pain, intensity and interference, on an 11 point Likert scale. More specifically, the ZBPI measures the presence and location of pain, the severity of the worst, least, and average pain in the last $24 \mathrm{~h}$, current pain intensity, use of medications, use of relief medications, and the interference of pain on general activity, mood, walking ability, normal work, relations with other people, sleep and enjoyment of life. The IZIQ, completed only at baseline, was used to complement the ZBPI, which was completed at all Study Visits, by assessing pain prior to study enrolment [16-19].

\section{Statistical analysis}

Descriptive statistics were produced for all relevant variables, including the mean and standard deviation for continuous scale variables, and frequency distributions for categorical variables. In addition to the total active population, all analyses were stratified by Work Time Loss Category (Work Time Loss (WTL) versus No Work Time Loss (NWTL)). Significance was determined $a$ priori at $p<0.05$, and a statistical trend was defined at $p<0.150$.

For assessment of the correlation between HRQoL (EQ-5D item scores: domain scores, overall summary score and VAS) and percentage of work effectiveness, the Pearson product-moment correlation was used. To identify predictors of HRQoL, mixed models with repeated measures were used, where individual EQ-5D scores throughout the follow-up period were the dependent variable, and the following covariates were considered: Work Time Loss Category (WTL versus NWTL), age at rash onset, gender, impaired immune status, presence of $\mathrm{HZ}$ complications, severity of rash at baseline (number of $\mathrm{HZ}$ lesions), worst pain score at baseline (based on the ZBPI "worst pain in the last $24 \mathrm{~h}$ " score), employment status (full-time versus part time), geographic region, and country income. Impaired immune status was defined as the use of high dose oral corticosteroids, invasive cancers (with the exception of CIS and non-melanoma skin cancer), HIV infection/ AIDS, immune deficiency, receipt of chemotherapy for cancer, prior or concurrent immunosuppressive therapy, or receipt of immunosuppressive therapy for organ transplant. Country income categories were determined according to the 2016 World Bank Income categories: upper-middle-income economies were defined as those with a gross national income (GNI) per capita of more than $\$ 4126$ but less than $\$ 12,735$; high-income economies were defined as those with a GNI per capita of $\$ 12,735$ or more [22].

\section{Results}

Baseline socio-demographic and disease characteristics

Baseline socio-demographic and disease characteristics are presented in Tables 1 and 2, respectively, and are presented overall, as well as stratified by whether or not 
Table 1 Baseline socio-demographic characteristics overall and by Work Time Loss Category

\begin{tabular}{|c|c|c|c|c|}
\hline \multirow[t]{2}{*}{ Variable } & \multicolumn{2}{|c|}{ Work time loss category } & \multirow[t]{2}{*}{ Overall ${ }^{b}$} & \multirow[t]{2}{*}{$p$-value } \\
\hline & Work time loss ${ }^{a}$ & No work time loss & & \\
\hline Total n, \% & $247(57.7)$ & $147(34.3)$ & 428 & - \\
\hline Age at rash onset, years, mean (SD) & $59.0(7.4)$ & $58.6(7.1)$ & $58.9(7.2)$ & 0.674 \\
\hline Gender, female, n (\%) & $126(51.0)$ & $71(48.3)$ & $217(50.7)$ & 0.602 \\
\hline \multicolumn{5}{|l|}{ Age category at rash onset, years, n (\%) } \\
\hline $50-59$ & $148(59.9)$ & $95(64.6)$ & $263(61.4)$ & \\
\hline $60-69$ & $79(32.0)$ & $39(26.5)$ & $129(30.1)$ & 0.520 \\
\hline$\geq 70$ & $20(8.1)$ & $13(8.8)$ & $35(8.2)$ & \\
\hline Not Available & $0(0.0)$ & $0(0.0)$ & $1(0.2)$ & \\
\hline \multicolumn{5}{|l|}{ Education, n (\%) } \\
\hline Primary school or less & $54(21.9)$ & $25(17.0)$ & $86(20.1)$ & \\
\hline High school & $77(31.2)$ & $51(34.7)$ & $139(32.5)$ & 0.485 \\
\hline College/University & $114(46.2)$ & $69(46.9)$ & $199(46.5)$ & \\
\hline Not Available & $2(0.8)$ & $2(1.4)$ & $4(0.9)$ & \\
\hline \multicolumn{5}{|l|}{ Geographic region, n (\%) } \\
\hline Asia & $77(31.2)$ & $52(35.4)$ & $140(32.7)$ & \\
\hline Latin America & $91(36.8)$ & $33(22.4)$ & $128(29.9)$ & 0.010 \\
\hline North America & $79(32.0)$ & $62(42.2)$ & $160(37.4)$ & \\
\hline \multicolumn{5}{|l|}{ Country category (income) $^{d}$} \\
\hline Upper-Middle & $94(38.1)$ & $42(28.6)$ & $146(34.1)$ & \\
\hline High & $93(37.7)$ & $64(43.5)$ & $171(40.0)$ & 0.079 \\
\hline Not Available & $60(24.3)$ & $41(27.9)$ & $111(25.9)$ & \\
\hline \multicolumn{5}{|l|}{ Employment status, n (\%) } \\
\hline Full time & $200(81.0)$ & $112(76.2)$ & $336(78.5)$ & \\
\hline Part time & $47(19.0)$ & $35(23.8)$ & $92(21.5)$ & 0.258 \\
\hline \multicolumn{5}{|l|}{ Number of hours work overall/week } \\
\hline$n$ & 246 & 146 & 411 & \\
\hline Mean (SD) & $39.3(16.0)$ & $38.3(17.6)$ & $38.8(16.5)$ & 0.395 \\
\hline \multicolumn{5}{|l|}{ Number of hours part time work/week } \\
\hline$n$ & 47 & 34 & 89 & \\
\hline Mean (SD) & $23.3(11.5)$ & $22.9(11.7)$ & $23.6(12.2)$ & 0.939 \\
\hline \multicolumn{5}{|l|}{ Number of hours full time work /week } \\
\hline$n$ & 199 & 112 & 322 & \\
\hline Mean (SD) & $43.1(14.4)$ & $43.0(16.4)$ & $43.0(15.0)$ & 0.703 \\
\hline \multicolumn{5}{|l|}{ Total number persons/household } \\
\hline$n$ & 243 & 145 & 421 & \\
\hline Mean (SD) & $2.8(1.6)$ & $3.0(1.9)$ & $2.8(1.7)$ & 0.420 \\
\hline \multicolumn{5}{|l|}{ Type of household, n (\%) } \\
\hline Apartment & $76(30.8)$ & $48(32.7)$ & $134(31.3)$ & \\
\hline House & $170(68.8)$ & $97(66.0)$ & $291(68.0)$ & 0.838 \\
\hline Other & $1(0.4)$ & $1(0.7)$ & $2(0.5)$ & \\
\hline Not Available & $0(0.0)$ & $1(0.7)$ & $1(0.2)$ & \\
\hline Work effectiveness, mean percent, (SD) & $50.3(31.6)$ & $71.4(27.8)$ & $56.0(32.0)$ & $<0.001$ \\
\hline
\end{tabular}


Table 1 Baseline socio-demographic characteristics overall and by Work Time Loss Category (Continued)

\begin{tabular}{llll}
\hline Work effectiveness category, $\mathrm{n}(\%)$ & & \\
$100 \%$ & $20(8.1)$ & $41(27.9)$ & $67(15.7)$ \\
$50-90 \%$ & $122(49.4)$ & $71(48.3)$ & $206(48.1)$ \\
$10-40 \%$ & $61(24.7)$ & $19(13.0)$ & $87(20.3)$ \\
$0 \%$ & $37(15.0)$ & $7(4.8)$ & $10(2.3)$ \\
Not Available & $7(2.8)$ & $9(6.1)$ & $18(4.2)$
\end{tabular}

a Patients with Work Time Loss were defined as those who reported missing work due to their shingles episode (entire day or part of a day) at baseline, as assessed by the WPQ

${ }^{b} 34$ patients did not have information on Work Time Loss Category

${ }^{\mathrm{C}}$ Asia = Korea, Taiwan, Thailand; Latin America = Argentina, Brazil, Costa Rica, Mexico; North America = Canada

${ }^{d}$ Country income classifications are based on the 2016 World Bank economic definitions [22]. High Income= Canada, South Korea, Taiwan, Argentina; Upper Middle Income= Brazil, Costa Rica, Mexico, Thailand

the patient experienced work time loss (WTL group vs. NWTL group). Of the 428 patients included in the analysis, 247 (57.7\%) reported losing work time due to their current HZ episode, with 147 patients (34.3\%), reporting no work time loss. Information on work time loss was not available for 34 patients (7.9\%) (Table 1). Overall, the mean (SD) age of rash onset was 58.9 (7.2) years, with over $60 \%$ of patients between the ages of $50-59$. No significant differences were reported in baseline socio-demographic characteristics, with the exception of geographic region, where the proportion of patients from Asian, Latin and North American countries differed across both the WTL and NWTL groups $(p=0.010)$ (Table 1$)$. The majority of patients $(n=336 ; 78.5 \%)$ were employed full time, and $92(21.5 \%)$ were part-time workers. Regarding work effectiveness, mean (SD) percent work effectiveness of patients in the WTL group was significantly lower compared to the NWTL group at baseline [50.3 (31.6) vs. $71.4(27.8) ; p<0.001$ ], with a significantly greater proportion of patients in the WTL group reporting a decrease in work effectiveness $(89.1 \%$ in the WTL group versus, $66.0 \%$ in the NWTL group; $p<0.001$ ) (Table 1 ). Overall, mean (SD) work time loss reported was 9.1 (15.6) days.

At baseline, rash was predominately absent or mild in severity $(68.0 \%, n=291)$, with significant differences observed between the WTL and NWTL groups $(p=0.014)$ in terms of the proportion of patients reporting no rash (22.7\% WTL vs. $12.2 \%$ NWTL), mild rash (43.3\% WTL vs. $58.5 \%$ NWTL), moderate rash (19.8\% WTL vs. $16.3 \%$ NWTL), and severe rash (14.2\% WTL vs. 12.2\% NWTL), and more patients in the NWTL group administered medication for their HZ episode (9.3\% WTL vs. $16.3 \%$ NWTL; $p=0.038$ ) (Table 2). Time from HZ onset was also significantly longer in the WTL group compared to the NWTL group [124.2 (458.3) vs. 79.6 (284.2) days; $p<0.001$.

Generally, at baseline, patients in the WTL group reported more severe disease parameters, with significant differences found for worst pain in the last $24 \mathrm{~h}[6.2$ (2.6)
WTL vs. 5.4 (2.6) NWTL; $p=0.004]$ and average and worst pain since rash experience [5.6 (2.3) WTL vs. 4.7 (2.2) NWTL, $p=0.002 ; 7.6$ (2.3) WTL vs. 6.5 (2.5) NWTL; $p<0.001$, respectively]; although differences in the proportion of patients experiencing post-rash pain were not significant $(p=0.349)$ (Table 2). In addition, a significant difference in worst pain (based on the ZBPI "worst pain in the last 24 h" score) was found between Work Time Loss Categories, with an overall greater proportion of patients in the WTL group reporting severe worst pain compared to the NWTL group (34.8\% vs. $22.4 \% ; p=0.041$ ) (Table 2). Duration of pain, i.e. from baseline to resolution, was also significantly higher in the WTL group compared to the NWTL group [89.9 (193.7) vs. 53.4 (51.4) days; $p<0.001$ ]. No significant differences were found between groups with regards to prodromal pain. Moreover, at baseline, patients in the WTL group had significantly lower $(p<0.001)$ overall HRQoL (EQ-5D summary score), greater problems with self-care and usual activities, and experienced higher pain/discomfort, when compared to patients in the NWTL group (Table 3). Pooled across all visits, significantly lower $(p<0.001)$ scores were seen in the WTL group for both overall HRQoL (EQ-5D summary score and VAS) and individual EQ-5D dimensions (Table 3).

\section{Correlation analyses}

Table 4 presents the correlation between percentage of work effectiveness and all EQ-5D items (dimension scores, summary score, and the VAS), overall, and by Work Time Loss Category. All correlation coefficients $(r)$ reported were found to be statistically significant $(p<0.001)$. Overall, percent work effectiveness was negatively correlated with all 5 dimension scores, whereas the EQ-5D summary score and VAS were positively correlated with percentage of work effectiveness $(r=0.427$ and 0.490 , respectively) suggesting that higher work productivity is associated with improved HRQoL. Similar results were observed for the WTL group, although a stronger correlation was observed for percent work effectiveness per the 
Table 2 Baseline disease parameters overall and by Work Time Loss Category

\begin{tabular}{|c|c|c|c|c|}
\hline \multirow[t]{2}{*}{ Variable } & \multicolumn{2}{|c|}{ Work Time Loss Category } & \multirow[t]{2}{*}{ Overall $^{b}$} & \multirow[t]{2}{*}{$p$-value } \\
\hline & $\overline{\text { Work Time Loss }^{a}}$ & No Work Time Loss & & \\
\hline Total n, \% & $247(57.7)$ & $147(34.3)$ & 428 & - \\
\hline \multicolumn{5}{|c|}{ Time from $\mathrm{HZ}$ onset, days } \\
\hline$n$ & 247 & 147 & 427 & \\
\hline Mean (SD) & $124.2(458.3)$ & $79.6(284.2)$ & $128.6(476.6)$ & $<0.001$ \\
\hline \multicolumn{5}{|c|}{ Time from $\mathrm{HZ}$ onset - categorical, n (\%) } \\
\hline Incident & $74(30.0)$ & $65(44.2)$ & $154(36.0)$ & \\
\hline Prevalent & $173(70.0)$ & $82(55.8)$ & $273(63.8)$ & 0.004 \\
\hline Not available & $0(0.0)$ & $0(0.0)$ & $1(0.2)$ & \\
\hline \multicolumn{5}{|c|}{ Pain before rash appearance, $\mathrm{n}(\%)$} \\
\hline Yes & $156(63.2)$ & $89(60.5)$ & $260(60.7)$ & \\
\hline No & $79(32.0)$ & $52(35.4)$ & $146(34.1)$ & 0.520 \\
\hline Not available & $12(4.9)$ & $6(4.1)$ & $22(5.1)$ & \\
\hline \multicolumn{5}{|c|}{ Average pain score before rash appearance ${ }^{c}$} \\
\hline$n$ & 155 & 88 & 258 & \\
\hline Mean (SD) & $4.9(2.6)$ & $4.4(2.5)$ & $4.7(2.6)$ & 0.148 \\
\hline \multicolumn{5}{|c|}{ Worst pain before rash appearance ${ }^{c}$} \\
\hline$n$ & 154 & 86 & 255 & \\
\hline Mean (SD) & $6.4(2.6)$ & $5.8(2.5)$ & $6.2(2.6)$ & 0.057 \\
\hline \multicolumn{5}{|c|}{ Pain since rash appearance, n (\%) } \\
\hline Yes & $222(89.9)$ & $130(88.4)$ & $376(87.9)$ & \\
\hline No & $14(5.7)$ & $12(8.2)$ & $33(7.7)$ & 0.349 \\
\hline Not available & $11(4.5)$ & $5(3.4)$ & $19(4.4)$ & \\
\hline \multicolumn{5}{|c|}{ Average pain since rash appearance ${ }^{c}$} \\
\hline$n$ & 222 & 129 & 375 & \\
\hline Mean (SD) & $5.6(2.3)$ & $4.7(2.2)$ & $5.3(2.3)$ & 0.002 \\
\hline \multicolumn{5}{|c|}{ Worst pain since rash appearance ${ }^{c}$} \\
\hline$n$ & 221 & 128 & 373 & \\
\hline Mean (SD) & $7.6(2.3)$ & $6.5(2.5)$ & $7.2(2.5)$ & $<0.001$ \\
\hline \multicolumn{5}{|c|}{ Pain in the last $24 \mathrm{hs}$} \\
\hline Yes & $224(90.7)$ & $126(85.7)$ & $380(88.8)$ & \\
\hline No & $23(9.3)$ & $20(13.6)$ & $47(11.0)$ & 0.178 \\
\hline Not available & $0(0.0)$ & $1(0.7)$ & $1(0.2)$ & \\
\hline \multicolumn{5}{|c|}{ Average pain in last $24 \mathrm{~h}^{c}$} \\
\hline$n$ & 224 & 126 & 380 & \\
\hline Mean (SD) & $4.5(2.5)$ & $4.0(2.3)$ & $4.3(2.4)$ & 0.062 \\
\hline \multicolumn{5}{|c|}{ Worst pain in last $24 \mathrm{~h}^{c}$} \\
\hline$n$ & 220 & 124 & 372 & \\
\hline Mean (SD) & $6.2(2.6)$ & $5.4(2.6)$ & $5.9(2.6)$ & 0.004 \\
\hline \multicolumn{5}{|c|}{ Worst pain score category, $\mathrm{n}(\%)^{\mathrm{d}}$} \\
\hline Mild & $43(17.4)$ & $35(23.8)$ & $83(19.4)$ & \\
\hline Moderate & $91(36.8)$ & $55(37.4)$ & $161(37.6)$ & 0.041 \\
\hline Severe & $86(34.8)$ & $33(22.4)$ & $127(29.7)$ & \\
\hline Not available & 27 (10.9) & $24(16.3)$ & 57 (13.3) & \\
\hline
\end{tabular}


Table 2 Baseline disease parameters overall and by Work Time Loss Category (Continued)

\begin{tabular}{|c|c|c|c|c|}
\hline \multicolumn{5}{|c|}{ Severity of rash (number of lesions), n (\%) } \\
\hline No rash & $56(22.7)$ & $18(12.2)$ & $84(19.6)$ & \multirow{5}{*}{0.014} \\
\hline Mild (1-20) & $107(43.3)$ & $86(58.5)$ & $207(48.4)$ & \\
\hline Moderate (21-50) & 49 (19.8) & $24(16.3)$ & $77(18.0)$ & \\
\hline Severe $(>50)$ & $35(14.2)$ & $18(12.2)$ & 59 (13.8) & \\
\hline Not available & $0(0.0)$ & $1(0.7)$ & $1(0.2)$ & \\
\hline \multicolumn{5}{|c|}{ Impaired immune status ${ }^{e}$} \\
\hline Yes & $18(7.3)$ & $9(6.1)$ & $29(6.8)$ & \\
\hline No & $229(92.7)$ & $138(93.9)$ & $399(93.2)$ & 0.658 \\
\hline \multicolumn{5}{|c|}{ Presence of $\mathrm{HZ}$ complication } \\
\hline Yes & $80(32.4)$ & $40(27.2)$ & $136(31.8)$ & \multirow{3}{*}{0.269} \\
\hline No & $166(67.2)$ & $107(72.8)$ & $291(68.0)$ & \\
\hline Not available & $1(0.4)$ & $0(0.0)$ & $1(0.2)$ & \\
\hline \multicolumn{5}{|l|}{ Medication for $\mathrm{HZ}$} \\
\hline Yes & $23(9.3)$ & $24(16.3)$ & $51(11.9)$ & \\
\hline No & $224(90.7)$ & $123(83.7)$ & 377 (88.1) & 0.038 \\
\hline
\end{tabular}

NWTL group versus the WTL group. This was evident in particular with regards to the EQ-5D overall summary score (NWTL: $r=0.402$ vs. WTL $r=0.209$ ) and the VAS (NWTL: $r=0.511$ vs. WTL: $r=0.260$ ).

\section{Multivariate analyses}

Upon adjusting for Work Time Loss Category, individual predictors of quality of life (both the EQ-5D summary score and the VAS) were time since HZ onset, worst pain score, severity of rash at baseline, geographic region, and country income (Table 5). Presence of $\mathrm{HZ}$ complications was also identified as a potential predictor of the VAS. Significant independent predictors of EQ-5D overall summary score identified in the saturated multivariate model are presented in Table 6. Work time loss was identified as a significant negative predictor of HRQoL with regards to both the EQ-5D overall summary score and the VAS $(p<0.001)$, as was moderate/severe worst pain score compare to mild pain $(p<0.001)$. Increased severity of rash was associated with significantly higher EQ-5D summary score, $(p=0.042$ for mild vs. no rash; $p=0.206$ for moderate vs. no rash; $p=0.017$ for severe vs. no rash), whereas country income (high vs. upper middle income levels) and presence of $\mathrm{HZ}$ complications, were both significant negative predictors $(p=0.003$, and $p=0.007)$ of the VAS.

\section{Discussion}

As reported previously, the results of this analysis demonstrate that shingles has a negative impact on the work and productive life of individuals [9-11]. Individuals experiencing work time loss reported lower health utility scores, at baseline and overall, than their non-work time loss counterparts, with work time loss identified as an independent negative predictor of both the EQ-5D summary scores and the VAS $(p<0.001)$. Decrease in work effectiveness was also negatively associated with quality of life overall, and in both the WTL and NWTL groups.

Additional predictors of quality of life identified were worst pain score, the presence of $\mathrm{HZ}$ complications, and country income (both complications and county income predictors of the EQ-5D VAS only). Although severity of rash was identified as a significant predictor of quality of life, the direction of the prediction is of interest, with more severe rash associated with improved HRQoL. This may be explained by the fact that, due to the inclusion of prevalent cases, there may not be a temporal association between rash assessment and disease onset. Thus, it could be argued that patients with no rash were those for whom rash healing had occurred, and that consequently, these patients experienced an overall longer time elapsed since disease onset. As it has been documented that prolonged pain of $\mathrm{HZ}$ has a significant 


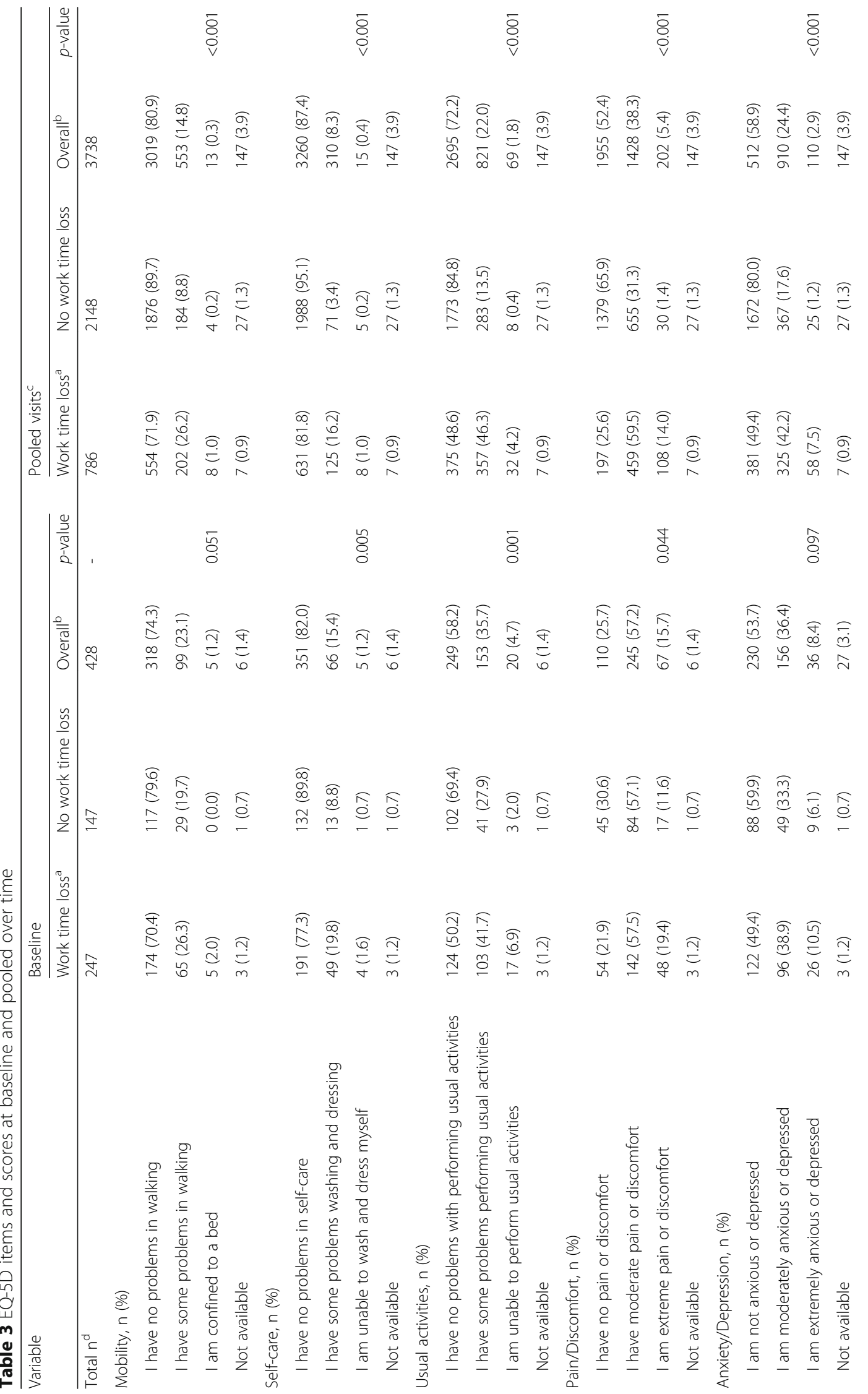




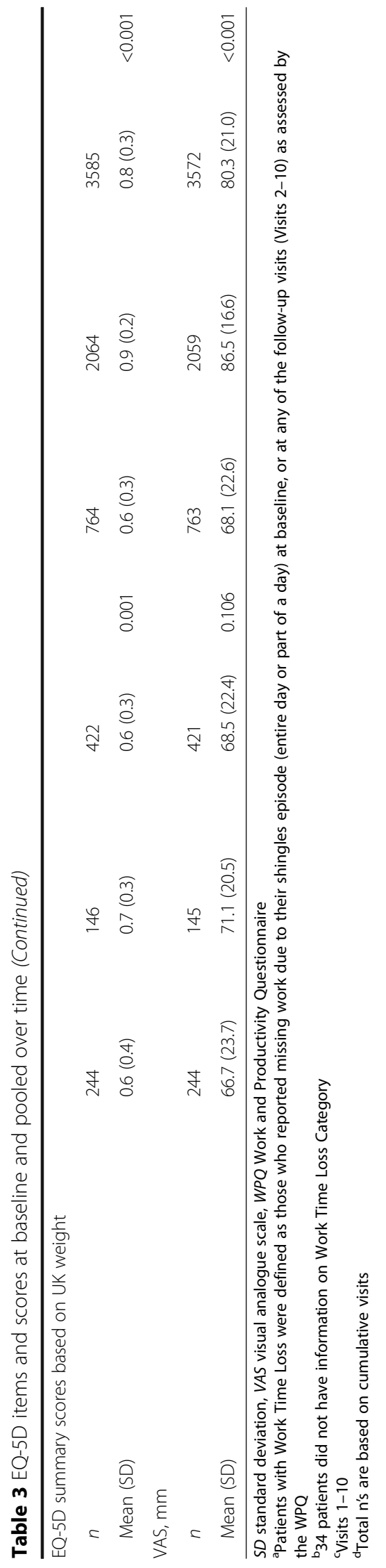


Table 4 Correlation between EQ-5D item scores and percentage of work effectiveness overall and by Work Time Loss Category

\begin{tabular}{|c|c|c|c|c|}
\hline Variable & Work Time Loss Category & EQ-5D item scores & Correlation coefficient $^{b}$ & $P$-value \\
\hline \multirow[t]{21}{*}{ Percent work effectiveness ${ }^{c}$} & \multirow[t]{10}{*}{ Overall } & Mobility & -0.265 & $<0.001$ \\
\hline & & Self-Care & -0.243 & $<0.001$ \\
\hline & & Usual activities & -0.401 & $<0.001$ \\
\hline & & Pain/Discomfort & -0.396 & $<0.001$ \\
\hline & & Anxiety/Depression & -0.331 & $<0.001$ \\
\hline & & EQ-5D summary scores based on UK weight & 0.427 & $<0.001$ \\
\hline & & EQ-5D VAS & 0.490 & $<0.001$ \\
\hline & & Mobility & -0.238 & $<0.001$ \\
\hline & & Self-Care & -0.158 & $<0.001$ \\
\hline & & Usual activities & -0.323 & $<0.001$ \\
\hline & \multirow[t]{7}{*}{ No Work Time Loss } & Pain/Discomfort & -0.356 & $<0.001$ \\
\hline & & Anxiety/Depression & -0.329 & $<0.001$ \\
\hline & & EQ-5D summary scores based on UK weight & 0.402 & $<0.001$ \\
\hline & & EQ-5D VAS & 0.511 & $<0.001$ \\
\hline & & Mobility & -0.148 & $<0.001$ \\
\hline & & Self-Care & -0.162 & $<0.001$ \\
\hline & & Usual activities & -0.245 & $<0.001$ \\
\hline & \multirow[t]{4}{*}{ Work Time Loss ${ }^{\mathrm{a}}$} & Pain/Discomfort & -0.161 & $<0.001$ \\
\hline & & Anxiety/Depression & -0.140 & $<0.001$ \\
\hline & & EQ-5D summary scores based on UK weight & 0.209 & $<0.001$ \\
\hline & & EQ-5D VAS & 0.260 & $<0.001$ \\
\hline
\end{tabular}

WPQ Work and Productivity Questionnaire, VAS visual analogue scale

aPatients with Work Time Loss were defined as those who reported missing work due to their shingles episode (entire day or part of a day) at baseline, or at any of the follow-up visits (Visits 2-10) as assessed by the WPQ

${ }^{b}$ Correlation coefficient was calculated based on Pearson's correlation measure

'Pooled over time (Visits 1-10)

effect on quality of life [6, 19], the residual post-rash pain experienced by these patients may have resulted in the reporting of lower health utility scores compared to patients assessed earlier in the course of their HZ episode, when rash manifestation was still evident. In our analysis, we have tried to adjust for the effect of time since $\mathrm{HZ}$ onset which was not found to have a significant impact on quality of life; however, it is possible that there may be residual confounding.

Overall $57.7 \%$ of patients reported missing work for an average (SD) of 9.1 (15.6) days. Days missed is therefore higher than that reported by Drolet et al. (3.4 days) and Singhal et al. (4 days) $[9,10]$, however discrepancies in study design may account for these differences: Drolet et al. evaluated HZ patients within 14 days of rash onset, whereas this study's inclusion of prevalent cases may have resulted in patient recall bias leading to an overestimation of HZ-related work time loss. In addition, at baseline, a higher proportion of patients in the WTL group reported a decrease in work effectiveness, indicating that patients who miss work due to their HZ episode are also less productive, and experience increased presenteeism.
Importantly, our findings show that patients reporting work time loss experience lower quality of life as compared to those not reporting work time loss, independently of differences in disease severity and other potential confounders. This suggests that people, at least some, consider work loss in their valuation of health states. Whether the effect of work time loss on quality of life is due to income loss and/or non-monetary factors such as psychological factors, could not be evaluated. In a review paper by Tilling et al., the proportion of patients who considered monetary losses in health state valuations when explicit instruction was not given was found to vary from 6 to $64 \%$ across the studies characterized [23]. In the same paper, significant differences in health care valuations were also observed between groups with and without instruction to consider income. Overall, Tiling et al. concluded that considerable inconsistencies exist between individuals in regards to considering income effects when valuing health states [23]. Due to differences in respondent characteristics, severity of health states values, measurement technique, and country of conduct, these results, as in the Tilling et al. review, were not consistent across all studies, and two 
Table 5 Repeated measures mixed model analysis assessing individual predictors of the EQ-5D summary score and EQ-5D VAS

\begin{tabular}{|c|c|c|c|c|c|c|c|c|}
\hline \multirow[b]{3}{*}{ Predictor } & \multicolumn{8}{|c|}{ EQ-5D Item } \\
\hline & \multicolumn{4}{|c|}{ EQ-5D overall summary score } & \multicolumn{4}{|l|}{ EQ-5D VAS } \\
\hline & Estimate $^{a}$ & SD & 95\% Cl for estimate & $\overline{p \text {-value }}$ & Estimate $^{a}$ & SD & 95\% Cl for estimate & $p$-value \\
\hline \multicolumn{9}{|l|}{ Work Time Loss Category } \\
\hline Work Time Loss ${ }^{\mathrm{b}}$ vs. No Work Time Loss & -0.234 & 0.010 & $-0.254,-0.215$ & $<0.001$ & -16.92 & 0.755 & $-18.40,-15.44$ & $<0.001$ \\
\hline \multicolumn{9}{|l|}{ Time from $\mathrm{HZ}$ onset - categorical } \\
\hline Prevalent vs. incident & -0.049 & 0.014 & $-0.076,-0.022$ & $<0.001$ & -3.811 & 1.339 & $-6.442,-1.181$ & 0.005 \\
\hline \multicolumn{9}{|l|}{ Age category at rash onset, years ${ }^{c}$} \\
\hline $60-69$ vs. $50-59$ & -0.002 & 0.015 & $-0.032,0.028$ & 0.898 & -1.562 & 1.465 & $-4.441,1.318$ & 0.287 \\
\hline$\geq 70$ vs. $50-59$ & -0.042 & 0.026 & $-0.092,0.008$ & 0.100 & -2.785 & 2.472 & $-7.643,2.073$ & 0.260 \\
\hline \multicolumn{9}{|l|}{ Worst Pain Category ${ }^{c, d}$} \\
\hline Moderate vs. mild & -0.084 & 0.013 & $-0.111,-0.058$ & $<0.001$ & -8.842 & 1.075 & $-10.95,-6.732$ & $<0.001$ \\
\hline Severe vs. mild & -0.287 & 0.018 & $-0.323,-0.251$ & $<0.001$ & -14.08 & 1.447 & $-16.92,-11.24$ & $<0.001$ \\
\hline \multicolumn{9}{|l|}{ Severity of rash (number of lesions) ${ }^{c}$} \\
\hline Mild (1-20) vs.no rash & 0.109 & 0.017 & $0.074,0.143$ & $<0.001$ & 10.646 & 1.707 & $7.292,14.000$ & $<0.001$ \\
\hline Moderate (21-50) vs. no rash & 0.100 & 0.021 & $0.058,0.141$ & $<0.001$ & 8.892 & 2.064 & $4.837,12.947$ & $<0.001$ \\
\hline Severe $(>50)$ vs. no rash & 0.095 & 0.024 & $0.049,0.142$ & $<0.001$ & 9.684 & 2.278 & $5.207,14.160$ & $<0.001$ \\
\hline \multicolumn{9}{|l|}{ Gender $^{\mathrm{c}}$} \\
\hline Male vs. female & -0.005 & 0.013 & $-0.032,0.021$ & 0.691 & 0.833 & 1.295 & $-1.711,3.377$ & 0.520 \\
\hline \multicolumn{9}{|l|}{ Impaired immune status ${ }^{c, \text { e }}$} \\
\hline Yes vs. no & -0.034 & 0.025 & $-0.084,0.016$ & 0.181 & -1.876 & 2.472 & $-6.734,2.983$ & 0.448 \\
\hline \multicolumn{9}{|l|}{ Presence of complications from $\mathrm{HZ}^{\mathrm{C}}$} \\
\hline Yes vs. no & -0.012 & 0.014 & $-0.040,0.016$ & 0.400 & -5.016 & 1.370 & $-7.707,-2.324$ & $<0.001$ \\
\hline \multicolumn{9}{|l|}{ Employment status $^{c}$} \\
\hline Full time vs. part time & 0.008 & 0.016 & $-0.024,0.040$ & 0.612 & -1.919 & 1.574 & $-5.011,1.173$ & 0.223 \\
\hline \multicolumn{9}{|l|}{ Geographic region ${ }^{c, f}$} \\
\hline Latin America vs. Asia & 0.030 & 0.017 & $-0.004,0.064$ & 0.191 & 3.245 & 1.628 & $0.047,6.443$ & 0.098 \\
\hline North America vs. Asia & -0.043 & 0.017 & $-0.076,-0.010$ & 0.011 & -5.146 & 1.583 & $-8.257,-2.035$ & 0.001 \\
\hline \multicolumn{9}{|l|}{ Country category (income) ${ }^{c, g}$} \\
\hline High vs. Upper Middle & -0.052 & 0.014 & $-0.079,-0.026$ & $<0.001$ & -6.616 & 1.290 & $-9.151,-4.081$ & $<0.001$ \\
\hline
\end{tabular}

SD standard deviation, $\mathrm{Cl}$ confidence interval, $\mathrm{HZ}$ Herpes Zoster, WPQ Work and Productivity Questionnaire, ZBPI Zoster Brief Pain Inventory, VAS visual analogue scale, CIS carcinoma in situ, HIV human immunodeficiency virus, AIDS acquired immune deficiency syndrome

${ }^{a}$ The estimate is the relative effect of the predictor on EQ-5D scores compared to the reference group

${ }^{b}$ Patients with Work Time Loss were defined as those who reported missing work due to their shingles episode (entire day or part of a day) at baseline, or at any of the follow-up visits (Visits 2-10) as assessed by the WPQ

'Predictors were adjusted by Work Time Loss Category

${ }^{\mathrm{d}}$ Worst pain score categories are based on the ZBPI "worst pain in the last $24 \mathrm{~h}$ " scores: mild worst pain $=\mathrm{ZBPI}$ scores 0 - $\leq 3$; moderate worst pain $=\mathrm{ZBPI}$ scores

$4-\leq 7$; severe worst pain $=$ ZBPI score $\geq 8$

e Defined as: use of high dose oral corticosteroids, invasive cancers (with the exception of CIS and non-melanoma skin cancer), HIV infection/ AIDS, immune deficiency, chemotherapy for cancer, prior or concurrent immunosuppressive therapy, and therapy for organ transplant

${ }_{\mathrm{f}}^{\mathrm{A}} \mathrm{sia}=$ Taiwan, Thailand, South Korea; Latin America = Argentina, Brazil, Costa Rica; Mexico; North America = Canada

${ }^{9}$ Country income classifications are based on the 2016 World Bank economic definitions [22]. High Income= Canada, South Korea, Taiwan, Argentina; Upper Middle Income= Brazil, Costa Rica, Mexico, Thailand

were identified in which a majority of respondents did consider income $[24,25]$. However, the two studies identified report that even with explicit instruction, the effects on income on health care valuations are disputable: Shiroiwa et al. found no significant differences in utility scores between individuals receiving no instruction regarding income, individuals instructed to consider income reduction, and individuals instructed to assume compensation for lost income [25], and Krol et al. found that explicit instruction on the inclusion of income effects had only some effect on time trade-off (TTO) valuations [24]. This suggests that the effect of lost income on utility scores is multifaceted, as it may involve social aspects such as human relationships and self-fulfillment, 
Table 6 Saturated multivariate repeated measures mixed model assessing independent predictors of the EQ-5D summary score and EQ-5D VAS

\begin{tabular}{|c|c|c|c|c|c|c|c|c|}
\hline \multirow[b]{3}{*}{ Predictor } & \multicolumn{8}{|c|}{ EQ-5D Item } \\
\hline & \multicolumn{4}{|c|}{ EQ-5D overall summary scores } & \multicolumn{4}{|l|}{ EQ-5D VAS } \\
\hline & $\overline{\text { Estimate }^{a}}$ & SD & $95 \% \mathrm{Cl}$ for estimate & $\overline{p \text {-value }}$ & $\overline{\text { Estimate }^{a}}$ & SD & $95 \% \mathrm{Cl}$ for estimate & $p$-value \\
\hline \multicolumn{9}{|l|}{ Work Time Loss Category } \\
\hline Work Time Loss ${ }^{\mathrm{b}}$ vs. No Work Time Loss & -0.102 & 0.014 & $-0.129,-0.074$ & $<0.001$ & -6.511 & 1.109 & $-8.687,-4.336$ & $<0.001$ \\
\hline \multicolumn{9}{|l|}{ Time from $\mathrm{HZ}$ onset - categorical } \\
\hline Prevalent vs. incident & -0.016 & 0.019 & $-0.052,0.020$ & 0.387 & -0.871 & 1.754 & $-4.320,2.578$ & 0.620 \\
\hline \multicolumn{9}{|l|}{ Worst Pain Category ${ }^{c}$} \\
\hline Moderate vs. mild & -0.083 & 0.014 & $-0.109,-0.056$ & $<0.001$ & -8.761 & 1.079 & $-10.88,-6.643$ & $<0.001$ \\
\hline Severe vs. mild & -0.290 & 0.018 & $-0.326,-0.254$ & $<0.001$ & -14.40 & 1.445 & $-17.23,-11.56$ & $<0.001$ \\
\hline \multicolumn{9}{|l|}{ Severity of rash (number of lesions) } \\
\hline Mild (1-20) vs. no rash & 0.044 & 0.021 & $0.002,0.086$ & 0.042 & 4.150 & 2.128 & $0.035,8.334$ & 0.052 \\
\hline Moderate (21-50) vs. no rash & 0.035 & 0.028 & $-0.019,0.090$ & 0.206 & 3.755 & 2.667 & $-1.489,8.999$ & 0.160 \\
\hline Severe ( $>50)$ vs. no rash & 0.070 & 0.029 & $0.012,0.128$ & 0.017 & 4.621 & 2.865 & $-1.014,10.255$ & 0.108 \\
\hline \multicolumn{9}{|l|}{ Country category (income) ${ }^{d}$} \\
\hline High vs. Upper Middle & -0.027 & 0.033 & $-0.091,0.038$ & 0.413 & -8.532 & 2.902 & $-14.24,-2.828$ & 0.003 \\
\hline \multicolumn{9}{|l|}{ Geographic region $^{\mathrm{e}}$} \\
\hline Latin America vs. Asia & 0.021 & 0.032 & $-0.042,0.083$ & 0.513 & -2.793 & 2.839 & $-8.374,2.788$ & 0.326 \\
\hline North America vs. Asia & 0.005 & 0.024 & $-0.043,0.052$ & 0.851 & 1.428 & 2.253 & $-3.001,5.856$ & 0.527 \\
\hline \multicolumn{9}{|l|}{ Presence of complications of $\mathrm{HZ}$} \\
\hline Yes vs. no & - & - & - & - & -4.509 & 1.654 & $-7.761,-1.257$ & 0.007 \\
\hline
\end{tabular}

$S D$ standard deviation, $C I$ confidence interval, VAS visual analogue scale, WPQ Work and Productivity Questionnaire

${ }^{a}$ The estimate is the relative effect of the predictor on EQ-5D scores compared to the reference group

${ }^{b}$ Patients with Work Time Loss were defined as those who reported missing work due to their shingles episode (entire day or part of a day) at baseline, or at any of the follow-up visits (Visits 2-10) as assessed by the WPQ

"Worst pain categories are based on the ZBPI "worst pain in the last $24 \mathrm{~h}$ " scores: mild worst pain $=$ ZBPI scores 0 - $\leq 3$; moderate worst pain $=$ ZBPI scores 4 - $\leq 7$; severe worst pain $=$ ZBPI score $\geq 8$

${ }^{d}$ Country income classifications are based on the 2016 World Bank economic definitions [22]. High Income= Canada, South Korea, Taiwan, Argentina; Upper Middle Income= Brazil, Costa Rica, Mexico, Thailand

${ }^{\mathrm{e}}$ Asia = Taiwan, Thailand, South Korea; Latin America = Argentina, Brazil, Costa Rica; Mexico; North America = Canada

rendering the effects of double counting in calculating cost-effectiveness negligible [25].

A limitation of the current analysis is that, due to the inclusion of prevalent cases, time since disease onset varied across patients, and may have led to recall bias in the assessment of work time loss since rash onset and the presence of prodromal pain. Furthermore, disease misclassification cannot be ruled out, as laboratory confirmation of VZV was not protocol-mandated. Finally, it is possible that selection bias towards including more severe $\mathrm{HZ}$ cases may have been introduced due to the fact that the patient population comprised of patients who sought out medical attention for their HZ episode.

\section{Conclusions}

The results of this study demonstrate that HZ-related reductions in work effectiveness and work time have a negative effect on the quality of life of actively employed individuals, independently of differences in disease severity and other potential confounders. However, it remains to be determined whether patients consider reductions in income when valuating health care states, as the results of studies assessing the unprompted inclusion of the effects of income have reported conflicting results $[25,26]$. In fact, the revised recommendations put forth by the Panel on CostEffectiveness in Health and Medicine, in a complete methodological shift, affirm that effects on productivity are unlikely to be captured in the denominator of most preference-based measures, citing inconclusive evidence [15]. Instead, in reference case analyses conducted under the societal perspective, the Panel advocates for the inclusion of these effects in the numerator of the ICER despite uncertainty with respect to the risk of double counting [15].

\section{Additional file}

Additional file 1: Work and Productivity Questionnaire. (PDF $14 \mathrm{~kb}$ ) 


\section{Abbreviations}

AIDS: Acquired immunodeficiency syndrome; Cl: Confidence interval; CIS: Carcinoma in situ; EQ-5D: Euro-QoL 5D questionnaire; GNI: Gross national income; HCRU: Health care resource utilization; HIV: Human immunodeficiency virus; HRQOL: Health related quality of life; HZ: Herpes Zoster; ICER: Incremental cost-effectiveness ratio; IZIQ: Initial Zoster Impact Questionnaire; NWTL: No work time loss; QoL: Quality of life; SD: Standard deviation; VAS: Visual analogue scale; VZV: Varicella zoster virus; WPQ: Work and Productivity Questionnaire; WTL: Work time loss; ZBPI: Zoster Brief Pain Inventory

\section{Acknowledgments}

Not applicable.

\section{Funding}

The design and execution of the MASTER studies, the analysis of the pooled results presented herein, and the medical writing of the current manuscript was funded by Merck \& Co. The authors are entirely responsible for the design of the analysis and the scientific content of the paper.

\section{Availability of data and materials}

As the data used to conduct these analyses are proprietary, we have respectfully chosen not to share the data on which the conclusions of the manuscript rely.

\section{Authors' contributions}

$E R, K K, K J$ and CA conceptualized the pooled analysis. ER designed and conducted the statistical analyses. ER and MS wrote the manuscript. KK, KJ, JS and CA contributed to major revisions of the manuscript. All authors reviewed the preliminary and final versions of the manuscript, and provided their input related to structure and content. All authors read and approved the final manuscript

\section{Competing interests}

ER, MS, and JSS are employees of JSS Medical Research, the CRO hired by Merck \& Co. to manage the individual MASTER studies contained in this pooled analysis, as well as provide statistical and medical writing services. KK reports being a former consultant for Merck and Co. TFT, HJC, JD, and AOC report personal fees from Merck \& Co. acting as Principal Investigators during the conduct of the MASTER studies. TFT also reports, outside the scope of this submitted work, personal fees from Johnson \& Johnson, Abbott, Pfizer, Leo pharmaceuticals, Novartis, Celgene, Galderma, Boehringer Ingelheim, GSK, Allergan, Tanabe, and non-financial support from Eli-Lilly. AOC also reports, outside the scope of this submitted work, personal fees from Bayer Health Care, Astellas Pharma, Merck Sharp \& Dohme, Abbott Laboratories, Aventis Pharma, and Sangui Labs. MCC, HM, KJ and CA are employees of Merck \& Co, or of a direct subsidiary.

\section{Consent for publication}

Not Applicable.

\section{Ethics approval and consent to participate}

All patients provided informed consent prior to their inclusion in each of the MASTER studies, which were conducted as per Good Clinical Practices and the tenets of the Declaration of Helsinki. All data were collected in an anonymous fashion and as per local data protection laws, and all studies were approved by local and central Ethics Boards, as required, for each participating site. Approval for this post-hoc analysis of available data was not required.

\section{Author details}

1JSS Medical Research, 9400 Henri-Bourassa W, St-Laurent, OC H4S 1N8, Canada. ${ }^{2}$ Clinical Research Center, Boston Children's Hospital, Harvard Medical School, 300 Longwood Ave., Boston, MA 02115, USA. Department of Dermatology, National Taiwan University Hospital, No. 7, Zhongshan South Road, Zhongzheng District, Taipei City 100, Taiwan. ${ }^{4}$ Division of Infectious diseases, Department of Internal Medicine, Korea University Guro Hospital, 145 Anam-ro, Seongbuk-gu, Seoul, South Korea. ${ }^{5}$ Clinical Infectious Disease Research Unit, Department of Clinical Tropical Medicine, Faculty of Tropical Medicine, Mahidol University, 420/6 Ratchawithi Road, Ratchathewi, Bangkok 10400, Thailand. ${ }^{6}$ Hospital Civil de Guadalajara Fray Antonio Alcalde, Calle Coronel Calderón \#777, El Retiro, 44280 Guadalajara, Jalisco, Mexico.
${ }^{7}$ Vaccines Latin America \& the Caribbean, MSD Corp., Av. San Jerónimo 369 Piso 8, Col. La Otra Banda, Mexico City CP 01090, Mexico. 'atin America Health Outcomes Research, MSD (I.A.) Corp., P.O. Box 3689, Carolina, PR 00984-3689, Puerto Rico. ${ }^{9}$ Center for Observational and Real-World Evidence, Merck \& Co., Inc., 2000 Galloping Hill Rd, Kenilworth, NJ 07033, USA. ${ }^{10}$ McGill University, 845 Sherbrooke Street W, Montreal, QC H3A 0G4, Canada.

Received: 11 May 2016 Accepted: 12 January 2017

Published online: 18 January 2017

\section{References}

1. Pinchinat S, Cebrian-Cuenca AM, Bricout H, Johnson RW. Similar herpes zoster incidence across Europe: results from a systematic literature review. BMC Infect Dis. 2013;13:170.

2. Kawai K, Gebremeskel BG, Acosta CJ. Systematic review of incidence and complications of herpes zoster: towards a global perspective. BMJ Open. 2014;4(6):e004833.

3. Yawn BP, Saddier P, Wollan PC, St Sauver JL, Kurland MJ, Sy LS. A populationbased study of the incidence and complication rates of herpes zoster before zoster vaccine introduction. Mayo Clin Proc. 2007:82(11):1341-9.

4. Johnson RW, Wasner G, Saddier P, Baron R. Herpes zoster and postherpetic neuralgia: optimizing management in the elderly patient. Drugs Aging. 2008;25(12):991-1006.

5. Katz J, Cooper EM, Walther RR, Sweeney EW, Dworkin RH. Acute pain in herpes zoster and its impact on health-related quality of life. Clin Infect Dis. 2004:39(3):342-8.

6. Lukas K, Edte A, Bertrand I. The impact of herpes zoster and post-herpetic neuralgia on quality of life: patient-reported outcomes in six European countries. Z Gesundh Wiss. 2012;20(4):441-51.

7. Schmader KE, Sloane R, Pieper C, Coplan PM, Nikas A, Saddier P, et al. The impact of acute herpes zoster pain and discomfort on functional status and quality of life in older adults. Clin J Pain. 2007;23(6):490-6.

8. Gater A, betz-Webb L, Carroll S, Mannan A, Serpell M, Johnson R. Burden of herpes zoster in the UK: findings from the zoster quality of life (ZQOL) study. BMC Infect Dis, 2014:14:402.

9. Drolet M, Levin MJ, Schmader KE, Johnson R, Oxman MN, Patrick D, et al. Employment related productivity loss associated with herpes zoster and postherpetic neuralgia: a 6-month prospective study. Vaccine. 2012;30(12):2047-50.

10. Singhal PK, Makin C, Pellissier J, Sy L, White R, Saddier P. Work and productivity loss related to herpes zoster. J Med Econ. 2011;14(5):639-45.

11. White RR, Lenhart G, Singhal PK, Insinga RP, Itzler RF, Pellissier JM, et al. Incremental 1-year medical resource utilization and costs for patients with herpes zoster from a set of US health plans. Pharmacoeconomics. 2009;27(9):781-92

12. Brazier J, Roberts J, Deverill M. The estimation of a preference-based measure of health from the SF-36. J Health Econ. 2002;21(2):271-92.

13. Gold M. Panel on cost-effectiveness in health and medicine. Med Care. 1996:34(12 Suppl):DS197-9.

14. Kind P, Dolan P, Gudex C, Williams A. Variations in population health status: results from a United Kingdom national questionnaire survey. BMJ. 1998;316(7133):736-41.

15. Sanders GD, Neumann PJ, Basu A, Brock DW, Feeny D, Krahn M, et al. Recommendations for conduct, methodological practices, and reporting of cost-effectiveness analyses: second panel on cost-effectiveness in health and medicine. JAMA. 2016;316(10):1093-103.

16. Tsai TF, Yao CA, Yu HS, Lan CC, Chao SC, Yang JH, et al. Herpes zosterassociated severity and duration of pain, health-related quality of life, and healthcare utilization in Taiwan: a prospective observational study. Int J Dermatol. 2015;54(5):529-36.

17. Aunhachoke K, Bussaratid V, Chirachanakul P, Chua-Intra B, Dhitavat J, Jaisathaporn K, et al. Measuring herpes zoster, zoster-associated pain, post-herpetic neuralgia-associated loss of quality of life, and healthcare utilization and costs in Thailand. Int J Dermatol. 2011:50(4):428-35.

18. Drolet M, Brisson M, Levin MJ, Schmader KE, Oxman MN, Johnson RW, et al. A prospective study of the herpes zoster severity of illness. Clin J Pain. 2010;26(8):656-66

19. Song $H$, Lee J, Lee M, Choi WS, Choi JH, Lee MS, et al. Burden of illness, quality of life, and healthcare utilization among patients with herpes zoster in South Korea: a prospective clinical-epidemiological study. Int J Infect Dis. 2014;20:23-30. 
20. Brooks R. EuroQol: the current state of play. Health Policy. 1996;37(1):53-72.

21. Coplan PM, Schmader K, Nikas A, Chan IS, Choo P, Levin MJ, et al.

Development of a measure of the burden of pain due to herpes zoster and postherpetic neuralgia for prevention trials: adaptation of the brief pain inventory. J Pain. 2004;5(6):344-56.

22. The World Bank. Country and Lending Groups [Internet]. 2016. Available from: http://data.worldbank.org/about/country-and-lending-groups\#Upper_ middle income.

23. Tilling C, Krol M, Tsuchiya A, Brazier J, Brouwer W. In or out? Income losses in health state valuations: a review. Value Health. 2010;13(2):298-305.

24. Krol M, Sendi P, Brouwer W. Breaking the silence: exploring the potential effects of explicit instructions on incorporating income and leisure in TTO exercises. Value Health. 2009;12(1):172-80.

25. Shiroiwa T, Fukuda T, Ikeda S, Shimozuma K. QALY and productivity loss: empirical evidence for "double counting". Value Health. 2013;16(4):581-7.

26. Brouwer WB, Koopmanschap MA, Rutten FF. Productivity costs

measurement through quality of life? A response to the recommendation of the Washington Panel. Health Econ. 1997;6(3):253-9.

Submit your next manuscript to BioMed Central and we will help you at every step:

- We accept pre-submission inquiries

- Our selector tool helps you to find the most relevant journal

- We provide round the clock customer support

- Convenient online submission

- Thorough peer review

- Inclusion in PubMed and all major indexing services

- Maximum visibility for your research

Submit your manuscript at www.biomedcentral.com/submit
( ) BioMed Central 